\title{
ECOS DA BREVIDADE - A FORMA DO CONTO E O QUE MUITO NOS DIZ: SILENCIAMENTO E VIOLÊNCIA NA NARRATIVA “IRMAN" (2009), DE SAMANTA SCHWEBLIN
}

Brenno Fernandes Soares

Carolina Rodrigues Guimarães

Resumo: O objetivo desse trabalho é analisar a forma do conto breve na narrativa "Irman", publicado na coletânea Pájaros en la boca (2009), de Samanta Schweblin, ao passo que propomos uma leitura crítica acerca dos aspectos sociais latentes na obra, como a banalização e silenciamento ante a morte do corpo feminino. Partese da hipótese de que as narrativas breves, apesar da curta extensão, apresentam muitas informações subjetivamente, possibilitando uma leitura plural do conto. A fim de analisar a forma do conto, apoia-se em teóricos e contistas que versam acerca da estrutura e elementos próprios da narrativa breve, tais como Edgar Allan Poe, Ricardo Piglia, Horacio Quiroga, Luzia de Maria. Esta pesquisa justifica-se pelo fato de que o conto moderno tem ganhado cada vez mais espaço na literatura e ao levantar temas sociais faz-se pertinente difundir tal gênero e a escrita feminina latino-americana, de modo que se faça conhecer cada vez mais.

Palavras-chave: Forma do conto. Samanta Schweblin. Narrativas breves. Silenciamento.

Resumen: El propósito de esta obra es analizar la forma del relato en la narrativa "Irman", publicada en la colección Pájaros en la boca (2009), de Samanta Schweblin, a la vez que proponemos una lectura crítica sobre los aspectos sociales latentes en la obra, como la trivialización y el silenciamiento ante la muerte del cuerpo femenino. Se basa en la hipótesis de que las narraciones cortas, a pesar de su corta duración, presentan mucha información subjetivamente, permitiendo una lectura plural del cuento. Para analizar la forma del cuento, se basa en teóricos y narradores sobre la estructura y elementos de la narración breve, como Edgar Allan Poe, Ricardo Piglia, Horacio Quiroga, Luzia de Maria. Esta investigación se justifica por el hecho de que el cuento moderno ha ganado cada vez más 
espacio en la literatura y al plantear temas sociales es apropiado difundir este género y la escritura femenina latinoamericana, para que sea cada vez más conocido.

Palabras clave: Forma del cuento. Samanta Schweblin. Narrativas cortas. Silenciamiento.

\section{INTRODUÇÃO}

A forma do conto tem sido objeto de análise e discussão de diversos teóricos e contistas, alguns com seus nomes mais atrelados à narrativa breve, tais como Edgar Alan Poe, Jorge Luís Borges, Horacio Quiroga. Além destes, destacamse Anton Tchekóv, Maupassant, Júlio Cortázar e Silvina Ocampo. Todos possuem certa característica comum em suas criações, a brevidade. Mais à frente retomaremos e aprofundaremos este traço fundamental do conto, por ora aproveitamo-nos de tais nomes para introduzir a contista e obra que nos servirá de objeto analítico. Salienta-se que, nem de longe, o panteão do conto apresentado em linhas anteriores foi mencionado apenas como pretexto para apresentação do corpus. Serão alguns destes que aqui nos guiarão e deles são algumas das teorias e fundamentos que embasaram esta pesquisa.

Samanta Schweblin (1978 - atualmente) é uma escritora notável que traz às suas obras um encontro entre a verossimilhança e o insólito, beirando o grotesco cômico em 
alguns de seus contos. Nascida em Buenos Aires, Schweblin é uma contista moderna, que dialoga com elementos sociais desde sempre pertinentes, mas muitas vezes silenciados, como o feminicídio e toda banalização que o cerca.

O conto intitulado "Irman", trabalhado neste artigo, faz parte do livro Pájaros en la boca (2009), que dá nome a um dos contos da coletânea - ou, melhor, o conto dá nome à coletânea. Em "Irman", Samanta Schweblin nos apresenta a história de duas pessoas, um sabemos chamar-se Oliver, quanto ao outro não há informações. Porém, é este último que nos servirá de narrador, o qual desempenha um papel quase de "testemunha" dos fatos. Chegam, os personagens, a um restaurante, no qual se deparam com um garçom "muy petiso" (SCHWEBLIN, 2009, p. 6), claramente atordoado, como se "alguien lo hubiese puesto ahí repentinamente y ahora él no supiera muy bien qué debía hacer" (SCHWEBLIN, 2009 , p. 6). O desconcerto do garçom, bem como sua estatura, causa graça a outros personagens, que aguardam uma bebida. Porém, ao retornar da cozinha de mãos vazias, o pequeno homem alega não alcançar a geladeira, - um ponto cômico à ou da (?) narrativa. O fato é que sua esposa está morta na cozinha e o garçom -, que ao final descobrimos chamar-se Irman - não alcança as coisas básicas pertinentes ao funcionamento de um restaurante. 
Optamos por dividir este trabalho em duas partes, sendo a primeira, destinada a analisar a forma do conto, e a segunda voltada à análise do corpus.

\section{A ESPINHA DORSAL DE "IRMAN": UMA ANÁLISE DA FORMA DO CONTO.}

Segundo nos conta Luzia de Maria em O que é conto? (2004), Mário de Andrade em determinado momento teria afirmado que "será sempre conto aquilo que seu autor batizou com o nome de conto" (2004, p. 19). Mas é certo que contistas de épocas diferentes já discorreram e buscaram formular a arte do conto, apresentando aspectos únicos que fazem a narrativa breve ser o que é. Estaria errado, então, Mário de Andrade? De forma alguma nos é de interesse responder tal pergunta, uma vez que na literatura não se trabalha com ideias exatas e resultados exatos; andamos além da margem, rumamos ao mar de possibilidades e interpretações. Nosso interesse, ademais, é apresentar as formulações acerca da narrativa breve já calcificadas nas teorias do conto.

O conto de Samanta Schweblin selecionado para a análise se relaciona às formulações apresentadas pelos teóricos do conto breve, uma vez que sua estrutura cria uma relação dialógica coerente à forma estrutural apresentada por estes. Observamos no corpus que (1) sua extensão é própria do 
conto breve, possibilitando a leitura em uma "assentada", (2) o início foi criado com vistas ao final, (3) conta duas histórias, ao passo que (4) a história dois mantém-se enigmática.

À luz das teorias aqui selecionadas, que versam sobre o conto, deparamo-nos com um consenso geral: a brevidade se faz aspecto importante ao gênero em questão. A extensão da arte do conto em prosa é um fator importante para que seja alcançado o êxito da narrativa, conforme Edgar A. Poe (1845) passamos a conhecer como "efeito" ou "unidade de impressão". Para o autor, uma narrativa cuja extensão ultrapasse o tempo "de uma assentada", perderia o efeito, uma vez que fatores externos, por certo, atrapalhariam ou desviariam a atenção do leitor, fazendo com que a interrupção do momento impossibilitasse alcançar a intensidade ali proposta. Assim, argumenta que

os interesses do mundo que intervêm durante as pausas da leitura modificam, desviam, anulam, em maior ou menor grau, as impressões do livro. Porém, a simples detenção da leitura por si só seria suficiente para destruir a verdadeira unidade. No conto breve, no entanto, o autor pode levar a cabo a totalidade de sua intenção, seja ela qual for. Durante a hora de leitura, a alma do leitor está nas mãos do escritor. Não há influências externas ou extrínsecas, produzidas pelo cansaço ou pela interrupção. (POE, 1845, p. 4) 
O contista ainda afirma que "todas as emoções intensas, por uma necessidade psíquica, são breves" (POE, 1845, p. 3), dispomo-nos de tal assertiva para submeter nosso objeto à forma do conto, o qual configura a forma breve evidenciada por Edgar A. Poe. Se constitui em uma narrativa que em apenas "uma assentada" se faz total, atingindo o efeito - ou impressão - pertinente à narrativa em prosa curta. Em seis páginas, ou até 30 minutos (ou menos) é possível experimentar o êxtase provocado pelo impetuoso conto de Samanta Schweblin.

Horacio Quiroga, em seu El manual del perfecto contista ressalta a preocupação de não cansar o leitor, de não o fazer perder tempo com algo que poderia ser evitado, uma vez que "el tempo es demasiado breve en esta miserable vida para perderlo de un modo más miseráble aún" (1925, p. 1190); nesta passagem Quiroga refere-se aos cansativos e longos diálogos que por vez foram utilizados a fim de iniciar uma narrativa, tornando-a fatigante a ponto de o leitor "saltar" antes de finalizar a leitura.

Há, desta forma, a necessidade de um bom início em um conto, que prenda a atenção do leitor, que o faça questionar os elementos ali presentes e o porquê de ali estarem. Em "Irman" (SCHWEBLIN, 2009), observamos elementos iniciais 
que colocam o leitor em uma situação de continuidade, como se começasse a observar uma história que já começara, mas não está descrita.

“Oliver manejaba" (SCHWEBLIN, 2009, p. 6), o narrador apresenta o personagem como se já nos fosse conhecido. Assim como Quiroga propõe em seu manual, podemos questionar: quem é Oliver? Por que ou para onde dirigia? De onde vinham? Perguntas que ficarão no ar, porém a provável inquietação do leitor diante destes questionamentos o desperta de forma inesperada ao que se segue. "Nadie lo sabe. Pero lá atención del lector há sido cogida de sorpresa, y esto constituye un desiderátum en el arte de contar" (QUIROGA, 1925, p. 1190.).

No entanto, vale destacar que para Quiroga o início de um conto deve ser criado pensando no final, uma vez que a tarefa elementar não é a primeira frase de um conto, mas sim o final. Para o autor, "el cuento empieza por el fin" (QUIROGA, 1925, p. 1189), assim a caminhada percorrida pelo contista deve ter sido estabelecida seu destino. Desta forma, o contista que não sabe, ou nem imagina, o final de seu conto, a frase que a este encerrará, tem grandes chances de se perder em sua narrativa, ao passo que a história pode tornar-se um fracasso, adotando frases 
previamente postuladas para que se chegue à amarração das pontas finais. Quiroga conta brevemente a situação em que um amigo se encontrava aos prantos, não conseguia terminar seu conto, pois faltava-lhe "tan solo la frase final" (1925, p. 1189). O contista - nosso contista - relata ainda que "podría asegurarse a ojos cerrados que toda historia que hace sollozar a su autor al escribirla, admite matemáticamente esta frase final: ¡Estaba muerta!" (QUIROGA, 1925, p. 1189).

Entretanto, segundo Quiroga, apesar de comumente pensar-se ser fácil criar um final, este é um pensamento equivocado. Assim como, o escritor que chorava, por não conseguir a almejada frase final, finalizar uma narrativa breve. Nessa perspectiva, Poe ressalta que para ser mantida a "exaltação da alma", é de grande complexidade, haja vista a importância de manter o ritmo da unidade de impressão. "Comenzaremos por el final. Me he convencido que del mismo modo que en el soneto, el cuento empieza por el fin. Nada en el mundo parecería más fácil que hallar la frase final para una historia que, precisamente, acaba de concluir. Nada, sin embargo, es más difícil" (QUIROGA, 1925, p. 1189).

"Irman" nos recebe com uma impressão de movimento, o conto inicia com um deslocamento - uma viagem, 
aparentemente, a estrada que vem de onde e vai para onde não sabemos, e nos apresenta um final que retorna ao asfalto, coloca novamente a ideia da movimentação. Quase caleidoscópica, de imagens e situações brevíssimas, uma vez que o não parar do automóvel só revela novas paisagens, novas visões. Retomar-se-á a ideia do movimento mais a frente, por ora manteremos nossa análise voltada à forma do conto. Visualiza-se "Oliver manejaba" (SCHWEBLIN, 2009, p. 6) em seu início, ao passo que ao final estamos novamente com os personagens na estrada, “-Mirá... Tendríamos que haber parado acá. [...] y se sacudió inquieto en el asiento, como si realmente lo lamentara." (2009, p. 11). Não estamos dizendo que todo conto breve seguirá seu começo abordando aspectos do final que a narrativa proporciona, ou vice-versa, ou mesmo que estes - início e final - serão interligados com palavras ou ideias similares, aqui buscamos demonstrar os elementos adotados por Samanta Schweblin para iniciar à narrativa e, posteriormente, brindar-nos com o final, revelando a ideia do conto em arco.

Fazer esse retorno do final ao espaço inicial do conto, revela o arco narrativo empregado por Schweblin, denotando um formato de 360 graus, uma vez que a história volta ao mesmo ponto do qual partiu, porém, revelando em 
seu desenrolar diversos acontecimentos. O conto "Irman" apresenta um arco que tem uma forma arredondada, que volta a si. Atrevemo-nos a dizer que revela uma ideia de um "eterno retorno narrativo".

Ricardo Piglia em Teses e novas teses sobre o conto (2004) afirma em um divertido primeiro parágrafo que "todo conto conta duas histórias", uma primeira que está na superfície, visível a todos. Nesse sentido, assim como Piglia, utilizamos da teoria do iceberg de Hemingway - enquanto a segunda está mais profunda, uma história secreta baseada no não dito, fica escondida, enigmática. Esconder a história 2 à sombra da história 1 é para Piglia "a chave para definir o caráter duplo do conto" (2004, p. 89). Tendo em mente a assertiva de que há em um conto duas histórias, fica a pergunta: qual a história cifrada no conto "Irman"? Para elucidar melhor a tese de Piglia e responder à questão, tomemos de análise o que se segue.

Oliver vai à cozinha, após o garçom dizer que sua mulher, a que alcança as coisas, está no chão. Depara-se com a mulher morta, estirada ao solo com uma concha na mão. Segundo o marido, a morta caiu. Mas o que de fato houve? Sabemos que a mulher realmente está morta, mas não nos é dado nenhum detalhe sobre o incidente. 
Temos então as duas histórias que afirma Piglia? 1) duas pessoas que estão em viagem chegam a um restaurante e a duras penas conseguem beber algo que lhes matasse a sede, enfim, depois de transtornos e incidentes, seguem viagem. 2) A cozinheira do restaurante está morta na cozinha; não se sabe como aconteceu ou o que acontecerá. O leitor é distanciado da narrativa ao passo que o narrador também se afasta. Tudo o que sabemos é o que nos é relatado pela "testemunha". Da mesma forma podemos pensar na história da mulher morta como uma narrativa à parte, que teve um início em dado momento, seja uma queda ou assassinato, o que motivou, - se é que houve motivo -, ou o que acontecerá depois.

Outra possibilidade de leitura é apresentar como a história secreta a situação relatada ao final do conto. Oliver e o narrador roubam uma caixa de madeira que estava atrás do balcão do restaurante, imaginando haver ali dinheiro, a qual "era liviana y demasiado chica para contener una fortuna. Tenía una llave de fantasía, como de cofre. La abrí" (SCHWEBLIN, 2009, p. 10). No entanto, quando abrem a caixa - e neste momento já estão na estrada - percebem que se tratam de lembranças.

Había un nombre grabado en la contratapa de madera, decía "Irman», y debajo había 
una foto del tipo muy joven, sentado sobre unas valijas en una terminal; parecía feliz. Me pregunté quién le habría sacado la foto. También había cartas encabezadas con su nombre: "Querido Irman», «Irman, mi amor», poesías firmadas por él, un caramelo de menta hecho polvo y una medalla de plástico al mejor poeta del año, con el logo de un club social. (SCHWEBLIN, 2009, p. 10)

O fragmento apresentado acima nos mostra parte da história de Irman, o garçom "petiso", que não alcançava ao menos a geladeira e dependia da esposa para tarefas simples. Passamos, então, a conhecer brevemente o protagonista? Era (foi) amado, esteve um dia feliz - indo para onde ou chegando de onde não sabemos, firmou-se como melhor poeta de um clube - que aspirações teria? "un caramelo de menta hecho polvo" (SCHWEBLIN, 2009, p. 10). Por que este doce era tão importante a ponto de ser guardado por tantos anos? Será que ganhara de alguém? Se sim, qual importância, ou que sentimentos despertariam essa pessoa em Irman? Inúmeras seriam nossas perguntas, nossos questionamentos em relação à vida deste homem que por pouco nem ao menos atravessaria a vida de nossos personagens viajantes caso optassem por outro caminho ou por não pararem em seu restaurante.

Segundo Piglia (2004): 
A versão moderna do conto [...] abandona o final surpreendente e a estrutura fechada; trabalha a tensão entre as duas histórias sem nunca resolvê-la. A história secreta é contada de um modo cada vez mais elusivo. O conto clássico à Poe contava uma história anunciando que havia outra; o conto moderno conta duas histórias como se fossem uma só. (PIGLIA, 2004, p. 91)

Tal como elucidado por Piglia, o conto de Samanta Schweblin não apresenta um final fechado, não dá ao leitor uma resolução às situações que até ali percorrera. Não é possível saber o que houve com a morta, ou com Irman. Podemos pensar mais: e quando Irman perceber que Ihe roubaram a caixa de lembranças? Que sentimentos não visualizaremos? Temos ainda a impressão de que a história corre, que continua mesmo após a última frase escrita. $\mathrm{O}$ conto em prosa apresenta essa característica de "contável", uma história que aconteceu e foi relatada. Ela tem continuidade, reforça a não finalização do conto moderno. Como Piglia parafraseando Borges "A arte de narrar [...] gira em torno desse duplo vínculo. Ouvir um relato que se possa escrever, escrever um relato que se possa contar em voz alta" (2004, p. 101).

Seja a segunda história do conto o relato da mulher morta na cozinha, ou mesmo o roubo da caixa de memórias de Irman, 
em ambos temos a mesma certeza: a morte da cozinheira é o elo que há entre as histórias. É a partir do conhecimento da morte da esposa, que o conto se desenrola em situações insólitas, beirando a anormalidade cotidiana. No entanto, essa dualidade entre real e irreal na obra de Schweblin, nos coloca à frente da próxima seção, na qual buscamos analisar o insólito, o grotesco e o não dito em “Irman” (2009).

\section{A BREVIDADE QUE MUITO NOS DIZ: ANÁLISE E INTERPRETAÇÃO DO CONTO "IRMAN"}

Iniciaremos esta seção retomando Luzia de Maria e seu livro O que é Conto (2004), a qual em determinado momento apresenta um conto do poeta alemão Bertold Brecht, intitulado "O menino Inerme", que relata brevemente a história de um menino que perdera duas vezes, para diferentes pessoas, o dinheiro que tinha, um conto cuja moral fala sobre injustiças (2004, p. 26-27). Enfim, Luzia chama atenção à brevidade deste conto:

Há casos em que o conto apresenta tal brevidade, levando ao limite máximo a economia verbal, que esfumam-se por completo os limites que poderiam demarcar as fronteiras do conto e as da simples anedota, direta, esquemática, completamente carente de descrições de local, situação, personagem, etc. [...] [porém], mesmo curta, a narrativa deu conta de construir um sentido, levando a 
percepção do leitor para além do espaço do dito, ou seja, para aquilo que "fala" mesmo no silêncio das entrelinhas. (MARIA, 2004, p. 26-27)

Sabemos aqui que a autora fala do conto de Brecht, ao passo que fala do conto em geral. Um conto mesmo que curto, breve, conta muita coisa, vai além do dizível, trabalha o subjetivo, conta mais de uma história, "[...] está claro que, mesmo com um mínimo de palavras, pode um conto dar conta do recado" (MARIA, 2004, p. 28). Cabe a nós, leitores, interpretar e ampliar nossa visão. Aqui propomos essa amplitude, olhar - analisar - as poucas linhas que constituem o conto de Schweblin, mas que muito nos dizem.

Em "Irman", como já vimos na seção 1, deparamo-nos com a história de uma mulher que está morta na cozinha de seu restaurante e seu marido, o garçom, não consegue atender dois clientes, porque não alcança a geladeira nem o fogão. Volvemos para o início do conto a fim de analisarmos o proposto.

O conto é narrado por um personagem que não nos é apresentado em momento algum. Sabemos apenas que viaja com Oliver, que já na primeira linha é introduzido. Ambos param em um restaurante. Ao depararem-se com o garçom pela primeira vez, é nítido o estranhamento dos 
personagens em relação à estatura do sujeito, "Un hombre apareció atrás de la cortina de plástico. Era muy petiso." (SCHWEBLIN, 2009, p. 6), e segue: “Regresó a la cocina y vimos su cabeza aparecer y desaparecer en las ventanas que daban al mostrador. Miré a Oliver, sonreía; yo tenía demasiada sed para reírme." (SCHWEBLIN, 2009, p. 6).

Oliver rir do sujeito demonstra o estranhamento que este Ihe causa, ademais a insensibilidade do personagem frente à fisionomia do garçom é um traço característico do risível. Segundo Bergson "o cômico exige algo como certa anestesia momentânea do coração para produzir todo o seu efeito" (1983, p. 8). Além de que perante ao pequeno homem, o personagem Oliver sente-se normal, como se Irman fugisse à normalidade física masculina. "É incontestável que certas deformidades têm sobre as demais o triste privilégio de poder, em certos casos, provocar o riso" (BERGSON, 1983, p. 15).

Pasó un rato, mucho más tiempo del que lleva elegir dos botellas frías de cualquier cosa y traerlas hasta la mesa, y al fin otra vez el hombre apareció. No traía nada, ni un vaso. [...] Hizo un gesto con la mano, confuso, como si fuera a dar alguna explicación, pero se interrumpió. Le pregunté qué pasaba, [...] Entonces se volvió hacia la cocina, y después, esquivo, dijo:

-Es que no llego a la heladera. 
Miré a Oliver. Oliver no pudo contener la risa y eso me puso de peor humor. (SCHWEBLIN, 2009, p. 6) ${ }^{1}$

Ao que se segue, o personagem retorna ao salão e, muito desconcertado, diz que não consegue alcançar a geladeira para servir aos clientes. Mais uma vez Oliver ri da situação anormal, evidenciando a citação anterior acerca da insensibilidade atrelada ao risível. O diálogo segue ao passo que o garçom revela que a esposa está caída ao chão da cozinha, sendo esta "la que agarra las cosas de la heladera" (SCHWEBLIN, 2009, p. 6). Oliver então se levanta rumo à cozinha, mas só sabemos o que de fato acontece no local quando nosso narrador testemunha - dirige-se também à cozinha:

Tuve que esquivarlo [Irman] para poder pasar cuando Oliver me llamó desde la cocina. Caminé despacio porque preví que algo estaba pasando. Corrí la cortina y me asomé. La cocina era chica y estaba repleta de cacerolas, sartenes, platos y cosas apiladas sobre estanterías o colgadas. Tirada en el suelo, a unos metros de la pared, la mujer parecía una bestia marina dejada por la marea. Aferraba con la mano izquierda un cucharón de plástico. (SCHWEBLIN, 2009, p. 6) $)^{2}$

1 Passou um tempo, muito mais tempo do que se leva para escolher duas garrafas geladas de qualquer coisa e trazê-las até a mesa, e afinal o homem apareceu outra vez. Não trazia nada, nem um copo [...]. Fez um gesto com a mão, confuso, como se fosse dar alguma explicação, mas a interrompeu. Perguntei-Ihe o que acontecia [...] Então se virou para a cozinha e depois, esquivo, disse:

- É que não alcanço a geladeira.

2 Tive de me esquivar para conseguir passar quando Oliver me chamou da cozinha. Caminhei rapidamente porque previ que alguma coisa estava acontecendo. Corri a cortina e entrei. A 
Os personagens tentam em vão mover a mulher e asseguram-se de que esta está morta. O narrador descreve a defunta como uma "besta marinha que havia sido deixada pela maré", ainda a chama, por vezes, de "gorda" e diz que mal conseguiram movê-la quando tentaram. Tal descrição demonstra uma discrepância entre o casal. Enquanto Irman era extremamente baixo - "Era mucho más petiso de lo que parecía. Creo que yo casi le llevaba tres cabezas" (SCHWEBLIN, 2009, p. 7), a esposa era comparada a um monstro marinho devido sua fisionomia.

O exagero também é uma característica do cômico discorrido por Bergson e a representação da esposa como "una bestia marina", bem como a fisionomia de Irman, beiram o grotesco, uma vez que segundo Bakhtin "o exagero, o hiperbolismo, a profusão, o excesso são [...] os sinais característicos mais marcantes do estilo grotesco" (1987, p. 265). No conto defrontamo-nos com o exagero quase disforme que há entre o casal: uma mulher muito grande e um marido muito pequeno. O cômico grotesco conceitua-se em:

Um fenômeno negativo preciso que é ridicularizado, alguma coisa que não devia ser [...] e é isso que Schneegans considera a propriedade essencial do grotesco: 
exagera caricaturalmente um fenômeno negativo.[...] no grotesco, o exagero é de um fantástico levado ao extremo, tocando a monstruosidade. (BAKHTIN, 1987, p. 267)

Como evidencia Domínguez em seu artigo "La monstruosidad en el orden de géneros: Samanta Schweblin y la subversión del discurso dominante" (2020), a monstruosidade é destacada no momento que o narrador descreve o corpo da mulher comparando-a a um monstro marinho, uma vez que o hibridismo mulher/animal cria a ideia do corpo monstruoso. No entanto, desaparece o traço de monstro quando os personagens descobrem que a mulher está realmente morta, como se retornassem à normalidade cotidiana (SCHWEBLIN, 2009, p. 9). Porém, o que de fato é monstruoso seria o exagero da fisionomia da mulher ou a banalização da morte? "El cadáver ha dejado de ser perturbador para los personajes (aunque pueda seguir siéndolo para los lectores) y en esta naturalización radica lo verdaderamente ominoso, que no es lo que el discurso dominante señala como monstruoso, sino lo que niega." (DOMÍNGUEZ, 2020, p. 9).

Podemos perceber a naturalização da morte da mulher no conto, como se fosse algo banal. É possível entrever em mais de um conto de Samanta Schweblin a recorrência do 
absurdo naturalizado. Tomemos de exemplo o conto "La pesada valija de Benavides" (Pájaros en la boca, 2009), no qual o personagem que dá nome ao conto mata a esposa, coloca-a dentro de uma mala e mostra ao psicanalista. Em momento algum Benavides é cobrado ou julgado pelo crime, acontece, porém, o contrário: ele é tido como um artista. Nos dois contos, deparamo-nos com a banalização da morte, especificamente, da morte feminina.

Questionamentos sobre as circunstâncias da morte da mulher não são possíveis de responder, no entanto visualizase no conto o quão banal torna-se a morte. Estamos diante do insólito proposto por Schweblin: seria normal ignorar uma morte bem à sua frente? Ou ainda, deparar-se com tal situação durante uma viagem? A fina linha da dualidade entre real e irreal é rompida, misturando elementos insólitos à realidade.

Mais questionamentos nos aparecem à medida que o conto segue. No momento em que o narrador está na cozinha junto à mulher morta, ele descreve que a geladeira que Irman não alcançava estava "ridiculamente" presa à parede com suportes, na altura dos armários. Ainda, em outra passagem entrevemos o narrador estranhar o fato de que não havia nada na parte debaixo do balcão. "Me sorprendió que no hubiera 
nada debajo de la mesada del mostrador" (SCHWEBLIN, 2009, p. 8). Por que não havia elementos ao alcance de Irman? Cabe um questionamento à relação que este mantinha com a esposa. Seria uma relação de dominação e o marido já cansado matara a mulher? Nunca saberemos.

Após constatarem que de fato a personagem está morta, Oliver e o narrador preocupam-se em comer algo, solicitando ao garçom que lhes prepare uma refeição. Interessa-lhes apenas fazer sua refeição, ignorando a mulher morta na cozinha. "Lo que principalmente llama la atención del lectoruna mujer que está muerta- parece un mero fondo a lo que realmente importa en el cuento" (SIMONSEN, 2014, p. 19). Para os personagens a morta deixa de ser um problema, agora que de fato os preocupa é como se alimentarão uma vez que o garçom não alcança o fogão ou a geladeira:

A ver, prepárenos un omelet - dijo Oliver.

El hombre se volvió hacia la cocina. Su rostro imbécil de estupor reflejaba los utensilios, las cacerolas, casi toda la cocina colgando de las paredes o sobre las estanterías.

-Ok, mejor no - dijo Oliver-, haga unos simples sándwiches, seguro que eso sí puede hacerlo.

-No -dijo el tipo-, no alcanzo a la sandwichera.

-No lo tueste, veo que no puedo pedirle tanto. Solo traiga el jamón, el queso, y un pedazo de pan. 
-No - dijo-, no -volvió a repetir negando con la cabeza; parecía avergonzado.

-Ok. Traiga un vaso de agua entonces.

Negó. (SCHWEBLIN, 2009, p. 9) ${ }^{3}$

Como já discorremos na primeira seção deste trabalho, o conto, para Piglia, contém mais de um relato, havendo algo de "incompreensível que acontece e está oculto" (SCHWEBLIN, 2009, p. 106), e em "Irman" a história da morte da esposa não nos é apresentada, sendo dúbia até para Oliver que questiona “¿Se cayó o la bajó?" (SCHWEBLIN, 2009, p. 7). Como não sabemos o que de fato houve, bem poderíamos estar frente a um feminicídio, assim como em "La pesada valija de Benavides". No entanto, o único momento em que aparece o questionamento acerca da morte da mulher é na citação colocada acima e ainda:

- No creo que haya sido él - dije en voz baja-, la necesita para llegar a la heladera, ¿o no?

-Llega solo...

- ¿Realmente creés que la mató?

- Puede usar una escalera, subirse a la

3 - Olhe só, prepare uma omelete para a gente - disse Oliver.

$\mathrm{O}$ homem se voltou rumo à cozinha. Seu rosto imbecilizado pelo estupor refletia os utensílios, as caçarolas, quase toda a cozinha pendurada nas paredes ou sobre as prateleiras.

- Ok, melhor não - disse Oliver. - Faça uns sanduíches simples, com certeza isso você pode fazer.

- Não - disse o sujeito -, não alcanço a tostadeira.

- Não precisa tostar, já percebi que não posso lhe pedir tanto. Só traga o presunto, o queijo e um pedaço de pão.

- Não - disse -, não - voltou a repetir, negando com a cabeça; parecia envergonhado.

- Ok, então traga um copo d'água.

Negou-se. 
mesa, tiene cincuenta sillas de bar... dijo señalando alrededor. Me pareció que hablaba alto a propósito así que yo bajé más la voz:

-Quizá sí es un pobre tipo. Quizá realmente es estúpido y ahora se queda solo con la gorda muerta en la cocina.

-¿Querés que lo adoptemos? Lo cargamos atrás y lo soltamos cuando llegamos. (SCHWEBLIN, 2009, p. 7) ${ }^{4}$

Como é possível entrever no fragmento acima, o nosso personagem-narrador-testemunha, desacredita ter sido Irman quem matou a esposa, devido sua "estupidez", sua baixa estatura e, principalmente, a desvantagem da força física - não dito. Irman é visto como frágil e fraco, e que não seria capaz de matar a esposa, que era o oposto dele fisicamente. Há nisso uma inversão do poder na sociedade conjugal, na qual "no plano da força física, resguardadas as diferenças individuais, a derrota feminina é previsível [...]" (SAFFIOTI, 2015, p. 76). Quando se invertem os polos que, patriarcalmente, definem o homem como dominante fisicamente e a mulher dominada, o sujeito - neste caso

\footnotetext{
4 Não acredito que tenha sido ele - respondi em voz baixa. - Precisava dela pra alcançar a geladeira, não?

- Ele alcança sozinho...

- Acredita realmente que a matou?

- Pode usar uma escada, subir na mesa, tem cinquenta cadeiras no bar... - respondeu, apontando ao redor. Parecia que falava alto de propósito, então baixei mais a voz.

- Talvez seja um pobre coitado. Talvez seja realmente estúpido e agora está sozinho com a gorda morta na cozinha.

- Você quer que o adotemos? Carregamos ele atrás e o soltamos quando chegarmos
} 
Irman - recebe características femininas, e passa a ser objeto de opressão dos mais fortes.

Além da risibilidade causada por Irman em Oliver, percebese, também, desde o início do conto sugestivas à violência contra o garçom, como quando o narrador "lê" a expressão de Oliver que dizia "«yo a este lo cago a trompadas»" (SCHWEBLIN, 2009, p. 7), ou ainda "Tuve ganas de pegarle" (SCHWEBLIN, 2009, p. 6). Aos olhos dos personagens, o garçom não se encaixa na ideologia de homem másculo, seja por sua estatura, seja pelo serviço que executa - comumente relacionado ao sexo feminino, seja pela dependência que tinha de uma mulher. Por isso, Oliver se impõe, ri, rebaixa-o a incapaz, "- Tiene [Irman] que hacerlo solo - dijo -, tiene que aprender" (SCHWEBLIN, 2009, p. 8).

Em determinado momento, sem saber o que fazer sem a esposa da qual dependia para executar os serviços, Irman sugere a Oliver que trabalhe para ele, uma vez que Oliver alcançava as coisas da cozinha. No entanto, Oliver sentese ofendido diante de tal proposta, haja vista que Irman seria seu patrão, o pagaria, exercendo desta forma um papel dominante. A situação muda de cômica para violenta, quando Irman oferece um bom salário a Oliver e refere-se ao automóvel do personagem: 
-Tengo plata. ¿Cuatrocientos la semana? Puedo pagarle. ¿Quinientos?

- ¿Paga quinientos la semana? ¿Por qué no tiene un palacio en el fondo? Este imbécil...

[...]

Lo vimos cerrar los pequeños puños como compactando una masa invisible que poco a poco se reducía entre sus dedos. Los brazos comenzaron a temblarle, se puso morado.

-Mi plata no le incumbe - dijo.

[...]

-Y por la camioneta que tiene - dijo el tipo mirando hacia la ruta-, por la camioneta que tiene se diría que manejo la plata mejor que usted.

-Hijo de puta - dijo Oliver, y se abalanzó sobre él. Alcancé a sostenerlo. (SCHWEBLIN, 2009, p. 9) ${ }^{5}$

Quando Irman fala sobre o dinheiro e o carro de Oliver, ele está abordando pontos que tocam o modelo de masculinidade, que em uma sociedade patriarcal são referências à virilidade e poder do homem. Oliver não poderia, enquanto normal frente ao garçom e arquétipo de masculinidade, aceitar que Irman projetasse a possibilidade

5 - Tenho dinheiro. Quatrocentos por semana? Posso lhe pagar. Quinhentos?

- Paga quinhentos por semana? E por que não tem um palácio ali no fundo? Puta imbecil...

Eu me levantei e parei atrás de Oliver, que ia dar-Ihe uma porrada a qualquer momento; creio que era detido apenas pela altura do sujeito. Vimos o infeliz cerrar os pequenos punhos como que compactando uma massa invisível que pouco a pouco se reduzia entre seus dedos. Os braços começaram a tremer. Ficou roxo.

- Meu dinheiro não the diz respeito.[...]

- E pela caminhonete que tem - disse o sujeito, olhando para a estrada -, pela caminhonete que tem eu diria que uso o dinheiro melhor que você.

- Filho da puta - respondeu Oliver, e se lançou sobre ele. Consegui segurá-lo. 
de ser seu patrão, de estar em posição superior diante dele. Diante disso, Oliver ameaça roubar o dinheiro de Irman:

- ¿Dónde está la plata?

Miré a Oliver sin entender.

- ¿Va a robarme?

- Voy a hacer lo que se me cante el orto, pedazo de mierda.

- ¿Qué hacés? - dije.

Oliver dio un paso, tomó al tipo de la camisa y lo levantó en el aire.

- ¿Dónde está tu plata, a ver? Oliver lo soltó.

[...] El tipo cayó, se acomodó la camisa.

-Ok - dijo Oliver-. O traes la plata, o te rompo la cara.

Levantó el puño bien cerrado y lo dejó a un centímetro de la nariz del tipo.

-Está bien - dijo el otro; dio un paso hacia atrás, despacio, cruzó la barra en sentido contrario al de la cocina y desapareció por una puerta. (SCHWEBLIN, 2009, p. 9) ${ }^{6}$

A violência mostra que Oliver não aceita perder sua posição de superioridade frente a um sujeito mais fraco, neste sentido "o próprio gênero acaba por se revelar uma camisa de força: o homem deve agredir, porque o macho

6 Onde está a grana?

Olhei para Oliver sem entender.

- Vai me roubar?

- Vou fazer o que me der na telha, monte de merda.

- Que é isso? - perguntei.

Oliver deu um passo, pegou o sujeito pela camisa e o levantou no ar.

- Onde está sua grana? [...] Oliver soltou-o. O sujeito caiu, arrumou a camisa.

- Ok - disse Oliver. - Ou você traz a grana ou quebro sua cara.

Levantou o punho bem fechado e o deixou a um centímetro do nariz do sujeito.

- Está bem - disse o sujeito; deu um passo para trás, lentamente. Cruzou o balcão em sentido contrário à cozinha e desapareceu por uma porta. 
deve dominar a qualquer custo" (SAFFIOTI, 2015, p. 90, grifo da autora). Para conseguir sair do papel de oprimido, Irman vale-se de uma arma de fogo, "un suplemento fálico (la escopeta) para restituir su masculinidad" (DOMÍNGUEZ, 2020, p. 13), passando assim a dispor do poder na situação. Se a agressão é própria do homem, faz-se necessário em uma situação de embate sobrepor-se à força do outro mesmo que optando por uma arma de fogo.

Diante da ameaça, os personagens saem do restaurante, mas não sem antes pegarem uma caixinha de madeira de uma das prateleiras do balcão, acreditando haver dinheiro. Já no automóvel passamos a saber o nome do garçom, até então não havia uma identidade a ele além de um garçom pequeno. Na tampa da caixa estava escrito "Irman", e dentro, deparamse com cartas, uma foto do sujeito, um caramelo antigo, uma medalha ao melhor poeta do ano, poesias escritas por ele. Nas cartas haviam escritos como "Querido Irman», "Irman, mi amor» (SCHWEBLIN, 2009, p. 10). Ao perceberem que não havia dinheiro, Oliver joga a caixa pela janela do carro. "De un manotazo, Oliver me quitó la caja y la tiró por la ventanilla. -¿Qué hacés? - me volví un segundo para ver las cosas ya desparramadas sobre el asfalto, algunos papeles todavía volando por el aire" (SCHWEBLIN, 2009, p. 10-11). 
Ao analisarmos a forma do conto na primeira seção deste trabalho, mencionamos a impressão caleidoscópica de situações e imagens breves para aqui a retomarmos. É neste momento que a plasticidade da imagem do carro em movimento, as cartas voando e os demais objetos caindo no asfalto, nos traz a ideia da imagem de um caleidoscópio, que fragmenta-se e muda rapidamente, não volvendo à imagem anterior. "Algunos papeles todavía volando por el aire", denota uma visão fragmentada, quase "confetizada" das cartas, que rapidamente fica para trás e não mais retorna. São lembranças de alguém que agora se perdem na autoestrada, memórias conservadas por tanto tempo - "um caramelo de menta hecho polvo" (SCHWEBLIN, 2009, p. 10), que agora são, definitivamente, parte do passado.

\section{CONSIDERAÇÕES FINAIS}

O conto breve percorreu um grande caminho desde Edgar Allan Poe aos contistas latino-americanos. De mesma forma, sofreu certas alterações em sua estrutura, como a entrega de um final cujo enigma não se resolve. Ainda assim, permanece a estrutura que o faz de fato uma narrativa breve. A curta extensão, a arte da prosa, o "escrever uma história que pode ser contada em voz alta". Traços característicos do conto tal qual o conhecemos. 
Optarmos por um conto cuja autora é uma mulher, que vem consagrando-se como grande escritora desta década, revelando a abertura que mulheres contistas estão tendo no cenário da literatura, demonstra a preocupação em evidenciar o valor literário que uma narrativa breve de autoria feminina dispõe. Samanta Schweblin percorre o insólito, o não dito e revela uma narrativa ímpar, que descobre sutilmente a casca dos problemas sociais, expondo-os ao leitor atento.

Analisar a forma do conto breve nos fez retornar à teoria do contista fantástico Edgar Allan Poe, em seu ensaio sobre a composição de "O corvo", nesse o escritor denota ao conto a necessidade da brevidade, da curta extensão para que o efeito, o êxtase do conto seja produzido no leitor. Podemos averiguar no conto de Samanta Schweblin a proposição de Poe, tratando-se "Irman" de uma narrativa breve e impactante.

Ancoramo-nos também nas teses de Piglia, em especial na assertiva de um conto conter duas histórias, sendo a segunda enigmática. Em "Irman" sugerimos duas leituras a fim de encontrar com a história secreta, uma ideia de possibilidades de leitura, tal qual a metanarrativa. Podemos indicar a cozinheira morta como a segunda história, ao 
passo que é possível que a narrativa secreta seja o próprio Irman e sua história omitida.

As possibilidades dentro do universo de um conto ultrapassam sua extensão. Pensar que em uma narrativa breve não há essência julgando apenas o número de linhas que esta contém, é deter-se à margem, enquanto há um mar perante si. Em "Irman" conseguimos visualizar manifestações sociais como a naturalização da morte (feminina), a violência imposta pelo gênero, a comicidade perante o diferente, o grotesco dos corpos disformes.

O conto "Irman" é pungente, à primeira vista estranho, confuso. Não se sabe exatamente o que está acontecendo: há um corpo na cozinha e discutem sobre comida. No entanto, Samanta Schweblin traça habilmente uma narrativa repleta de omissões -não dito, que revela pouco a pouco o real e o insólito presentes na obra. Por mais que possa parecer irreal ignorar totalmente um corpo morto a sua frente, visualizamos esse comportamento em nossa sociedade que perpetua a ideologia patriarcal e se silencia perante a morte feminina.

\section{REFERÊNCIAS}

BAKHTIN, Mikhail M. A imagem grotesca do corpo em Rabelais e suas fontes. In: BAKHTIN, Mikhail M. A cultura popular na Idade Média e no Renascimento: o contexto de François Rabelais. São Paulo: HUCITEC; Brasília: Editora da Universidade de Brasília, p. 265-322, 1987. 
BERGSON, Henri. O riso: ensaio sobre a significação do cômico. Rio de Janeiro: Zahar Editores S.A., 1983.

DOMÍNGUEZ, Silvana Castro. La monstruosidad en el orden de géneros: Samanta Schweblin y la subversión del discurso dominante. Prácticas de oficio Investigación y reflexión en Ciencias Sociales, v. 1, n. 24, p. 5-20, enero/junio de 2020.

MARIA, Luiza de. O que é Conto. São Paulo: Brasiliense, 2004.

PIGLIA, Ricardo. Teses sobre o conto e Novas teses sobre o conto. In: PIGLIA, Ricardo. Formas Breves. São Paulo: Companhia das Letras, p. 87-114, 2004. POE, Edgar A. (1845). A filosofia da composição. Tradução de Oscar Mendes e Milton Amado. Disponível em: https://edisciplinas.usp.br/pluginfile. php/2544953/mod resource/content/1/Poe.pdf. Acesso em: 7 mar. 2021. QUIROGA, Horacio. El manual del perfecto cuentista. In: QUIROGA, Horacio. Todos los cuentos. Disponible en: https://edisciplinas.usp.br/ pluginfile.php/4492523/mod resource/content/2/Quiroga.\%20el\%20 amnual.pdf. Acesso em: 7 mar. 2021.

SAFFIOTI, Heleieth. Gênero patriarcado violência. 2. ed. São Paulo: Expressão Popular: Fundação Perseu Abramo, 2015.

SCHWEBLIN, Samanta. Pájaros en la boca. Editor digital: Titivillus, p. 6-11, 2009. Disponible en: https://www.epubgratis.vip/pajaros-en-laboca-samanta-schweblin. Acceso en: 7 mar. 2021.

SIMONSEN, Agnes. En el límite entre lo real e irreal - Lo extraño y lo que no se dice en tres cuentos de Samanta Schweblin. 2014. 31f. Tese (bacharelado em Literatura). Lunds Universitet, Lund, Suécia. 2014. Disponible en: https://lup.lub.lu.se/luur/download?func=downloadFile\&r ecordOld $=4530275 \&$ fileOId $=4530282$. Acceso en: 7 mar. 2021.

\section{Carolina Rodrigues Guimarães}

Mestranda em Estudos da Linguagem, pela Universidade Federal de Goiás-Regional Catalão (UFG-RC).

E-mail: carolinarodrigues279@outlook.com

Lattes: http://lattes.cnpq.br/6088753338031955 


\section{Brenno Fernandes Soares}

Doutorando em Estudos de Literatura, pela Universidade Federal de São Carlos (UFSCar), bolsista CAPES.

Membro do grupo de pesquisa Estudos sobre Literatura, Política e Memória.

E-mail: brennofsoares@hotmail.com

Lattes: $\underline{\text { http://lattes.cnpq.br/6780493854348403 }}$ 